\title{
Condições materiais e a eficácia da informática aplicada à educação: a culpa é do professor?
}

\author{
Andrea L. M. da Costa ${ }^{1}$, Fernando José de Almeida ${ }^{2}$ \\ ${ }^{1}$ Departamento de Informática - Instituto Federal de Educação, Ciência e Tecnologia do \\ Pará (IFPA) Belém - PA/BR \\ ${ }^{2}$ Programa de Pós-graduação em Educação: Currículo da PUC-SP/BR \\ alilian.costa@gmail.com, fernandoalmeida43@gmail.com
}

\begin{abstract}
There is a mismatch between the digital resources available today and effective educational outcomes, especially in public schools. One reason which may be related to this question refers to the support material available at these schools. This paper analyzes the conditions for effective use of computer classrooms of 11 schools and presents not only the physical aspects, delayed schedules, and facilities problems difficult an effective application, but the personal and professional work of teachers join the problem. We try to get up here and point the real difficulties in addressing the problem by showing the origins and pointing directions.
\end{abstract}

Resumo. Observa-se um descompasso entre os recursos digitais disponíveis hoje e resultados educacionais efetivos, em especial, nas escolas públicas. Uma causa que pode estar relacionada a essa questão refere-se ao suporte material disponível nessas escolas. Este trabalho analisa as condições efetivas de uso das salas de informática de 11 escolas e apresenta que não apenas os aspectos físicos, retardos de cronogramas e problemas de instalações dificultam uma efetiva aplicação, mas que as condições pessoais $e$ profissionais de trabalho do professor se juntam à problemática. Tenta-se aqui buscar e apontar as dificuldades reais para enfrentar o problema, mostrando-lhe as origens e apontando direções.

\section{Introdução}

As motivações e explicações da entrada da informática na educação escolar são múltiplas e bem fundadas. Só há lógica em inserir logo os mobiles, as TV digitais, as redes sociais, as escritas coletivas em nuvens, os jogos colaborativos nas redes escolares, se houver um consistente projeto pedagógico. A verdade é que os efeitos imediatos prometidos e as transformações miraculosas não acontecem. As pesquisas provam, os índices resultantes de provas nacionais não conseguem evidenciar os milagres. Então, à moda dos filmes ingleses de investigação de um crime aparece o culpado: não mais o mordomo, mas o professor! 
É na perspectiva de localizar a razão que fundamenta as dificuldades de implantação e verificação da entrada eficaz da informática na escola que acontece esta pesquisa.

Separar para compreender é um modo de ver a ciência. Verificar as condições físicas, ideológicas e curriculares faz parte deste método de constatação da construção da história das tecnologias na escola e no currículo desta atual escola brasileira.

Mas não basta compreender as demoras e as dificuldades. Começa-se este artigo defendendo o uso das TIC — Tecnologias da Informação e da Comunicação — na escola pública como um direito humano e como uma conquista democrática a ser realizada pela tardia escola republicana brasileira.

\section{Tecnologia como humanização}

O trabalho educativo deve procurar reduzir a discrepância entre o conhecimento histórico e coletivamente desenvolvido pela humanidade e a sua apropriação pelo indivíduo; o que deve ocorrer por meio da transmissão-assimilação do saber sistematizado Saviani (2008). O papel conferido à escola, exposto pelo autor, é em última instância, o de desenvolver nos estudantes o domínio sobre determinado conhecimento, de maneira que esse seja incorporado na forma de uma segunda natureza.

Álvaro Vieira Pinto (2005, p.747) na mesma direção defende que "Cabe ao filósofo, ao educador, ou ao técnico crítico, possuidores da correta compreensão da dialética da história, empreender uma ardorosa defesa ao mesmo tempo da tecnologia e da personalidade humana".

O processo de humanização do indivíduo significa a incorporação dos elementos culturais necessários à formação, não somente para o trabalho, mas, igualmente, para o exercício da cidadania. Frente a esse posicionamento Saviani coloca como objeto da educação: "a identificação dos elementos culturais que precisam ser assimilados pelos indivíduos da espécie humana para que eles se tornem humanos e, de outro lado e concomitantemente, a descoberta das formas mais adequadas para atingir esse objetivo". (SAVIANI, 2008, p. 13). No que diz respeito ao segundo aspecto do trabalho pedagógico, pode-se defender a importância de se definirem e planejarem os meios mais adequados para que todos os alunos, no interior da escola, possam se apropriar gradativamente do conhecimento elaborado produzido pela humanidade. "Trata-se da organização dos meios (conteúdos, espaço, tempo e procedimentos) através dos quais, progressivamente, cada indivíduo singular realize, na forma de segunda natureza, a humanidade produzida historicamente" (Idem, op. cit., p. 14). Sobre essa percepção do domínio que deve haver no processo do trabalho Lukács $(2004$, p.98) assinala que ela pode ser alcançada desde que:

[...] tanto en la posición del fin como en la elección de sus médios, se orienta continuamente en dirección a captar de acuerdo con su objetivo ser em sí todo lo que se vincula con el trabajo, y a relacionarse con elle - con el fin y com sus médios - de acuerdo con su ser en sí. En ello no solo se encuentra contenida la intención hacia un reflejo objetivo, sino también el empeño en descartar todo lo meramente instintivo, emotivo, etc, que podría perturbar la comprensión objetiva. 
A partir desse posicionamento compreende-se que a introdução sistematizada das recentes tecnologias, para as diferentes modalidades de ensino, está ligada potencialmente a essa busca de estratégias educacionais mais adequadas, desde que ocorra no âmbito de um projeto coeso de humanização. É fundamental que se dê a devida importância aos conteúdos curriculares, que uma vez definidos coletivamente (parâmetros curriculares oficiais, corpo pedagógico da escola, coletivos docentes das diferentes disciplinas) constituem a intenção a ser atingida, dentre outras formas, pela integração dos novos recursos tecnológicos disponíveis no ambiente escolar. Portanto, anteriormente à adesão, a um determinado recurso tecnológico, é da máxima importância a busca pela compreensão do objeto como um todo, apreendendo dele todas as suas potencialidades. A apropriação inadequada de recursos tecnológicos no ambiente escolar pode tornar seu uso enfadonho e de pouca ou nenhuma correlação com os assuntos abordados em sala de aula. Ao contrário, por exemplo, no campo da matemática determinados softwares, se forem bem apresentados e aplicados, aumentam o interesse dos alunos, não tão-somente pela nova tecnologia, mas, prioritariamente, pelo objeto de estudo nessa área do conhecimento. Por meio, por exemplo, do software livre GeoGebra o ensino da geometria analítica pode ser mais significativo. A partir do uso desse recurso o aluno poderá constatar, por exemplo, que a simples alteração de um determinado parâmetro dentro de uma equação implica na alteração do formato ou direção do gráfico associado a esta mesma equação, possibilitando assim ao aluno fazer uma revisão dos conceitos, métodos e aplicações, e melhor compreendendo o fenômeno matemático. Um estudo desenvolvido por Costa et al. (2008) voltado a crianças com histórico de reincidente dificuldade na aprendizagem de conceitos aritméticos, demonstrou que por meio do uso adequado do software Arit - desenvolvido com base na paradigma de equivalência - foi possível contribuir para o processo de ensino aprendizagem da operação fundamental de adição. Outra questão posta é com relação à variedade de aplicativos e equipamentos disponíveis no mercado; a escolha desses também envolve conhecimento por parte do corpo pedagógico, pois não raro muitos já trazem consigo uma série de vantagens técnicas e concepções sócio-políticas. Em se tratando da atividade de ensino, dois aspectos sobre a matéria prima a ser operada são igualmente importantes para os docentes: o domínio sobre os conteúdos essenciais vinculados às suas disciplinas, e, ao mesmo tempo, a devida apropriação das ferramentas pedagógicas tal como ela se apresenta na escola. A segurança sobre esse dois componentes tem decisiva importância para que seja possível a exploração de seus recursos e formas de uso de maneira a torná-los um instrumento para o alcance dos objetivos escolares. O cenário atual nos traz um rico conjunto de objetos em versão eletrônica - livro eletrônico, lousa digital, mesa educacional, mouse remoto, computadores portáteis, iPad, e tantos outros - novas formas de registro e difusão de informações, por meio do contínuo e atual desenvolvimento tecnológico, com potencial para área educacional, aplicáveis nos mais variados contextos. Se as qualidades são tantas, pergunta-se, por que é tão difícil sua implantação? Resistência dos professores, inadequação com o currículo, pouca vontade política dos governantes?

Observa-se um descompasso entre recursos digitais disponíveis hoje e resultados educacionais efetivos, em especial, nas escolas públicas. Uma causa que pode estar relacionada a essa questão refere-se ao suporte material disponível nessas escolas. Este trabalho, a partir de um conjunto de 11 escolas, explicita as condições efetivas de uso 
das suas salas de informática e busca apontar as dificuldades reais de enfrentar o problema, mostrando-lhe as origens e apontando direções.

\section{O procedimento da pesquisa}

Foram utilizadas, como técnica para coleta de dados, entrevistas. Essa forma de colher o depoimento das pessoas, própria das ciências humanas, é muito útil para obter informações sobre o problema em questão. De acordo com Soriano (2004, p.153) "esse instrumento permite que fontes chaves de informação sejam selecionadas, de forma que essas, ao serem dotadas de experiências e conhecimentos relevantes sobre o tema em estudo possam fornecer dados que outras pessoas desconhecem total ou parcialmente". Dessa forma as entrevistas aqui realizadas tiveram por finalidade aprofundar questões e esclarecer problemas sobre o fenômeno pesquisado. Essa característica é permitida, especialmente, nas não totalmente estruturadas, onde não há imposição de uma ordem rígida de questões (Lüdke e André, 1986). Nesta fase da pesquisa foi empregada a técnica de entrevista semi estruturada, com um conjunto de perguntas-guia relativas às questões quantitativas e qualitativas.

Todas as entrevistas ocorreram nas escolas onde os professores desenvolviam suas atividades de ensino. As entrevistas, quando do consentimento do entrevistado, foram gravadas, durante as quais também se realizaram anotações. Teve-se como objetivo aqui identificar elementos para se compreender as condições materiais disponíveis nas salas de informática, tomando-se para análise os seguintes aspectos: a disponibilidade nesse espaço de quadro magnético, número de computadores disponíveis, bem como, os que efetivamente estavam em funcionamento por ocasião da pesquisa e outros recursos que porventura estivessem em uso e/ou disponível. Fez parte desse roteiro verificar qual o procedimento para a utilização da sala de informática (SI) e a frequência de uso dela pelos docentes. Foram privilegiadas também questões referentes à manutenção dos equipamentos eletrônicos.

As entrevistas foram realizadas com professores, lotados ou não, nas salas de informática e gestores das escolas públicas estaduais. A amostra para esta pesquisa abrangendo o ensino fundamental e médio, por representarem os níveis de ensino foco de investimentos das TIC - foi constituída de 11 escolas. A escolha das escolas levou em consideração: localização (de forma que fossem representados os diferentes bairros do município); quantidades de alunos atendidos (foram contempladas escolas de médio e grande porte). Essa escolha foi motivada por se entender que a escola pública, por meio de investimentos públicos adequados, é a que possui o papel de promoção da universalização da educação.

\section{A exposição e discussão dos dados}

Com relação às condições de infraestrutura disponíveis nas salas de informática das 11 escolas as visitas apontaram várias carências e impasses para o efetivo aproveitamento pedagógico desse espaço. Exemplo emblemático desse cenário foi observado no estado de conservação da sala de informática, nas cadeiras impróprias e em quantidades insuficientes, na baixa disponibilidade de computadores, na indisponibilidade de software para aprendizagem, na inoperante conexão à internet, e no insuficiente suporte técnico ao ambiente informatizado da escola. 
Nas 11 escolas visitadas cada uma possui apenas um laboratório para atender a todas as suas turmas, cujo número varia de acordo com o porte da escola. As escolas de médio porte, por exemplo, para o turno da manhã têm aproximadamente 16 turmas enquanto as de grande porte atendem em torno de 25 turmas. Tal restrição impõe à escola a necessidade de agendar horários para a utilização dos computadores e torna-se um limitador ao uso da informática na escola. No quadro 3 é apresentada a proporção aluno/computador1 para as escolas pesquisadas.

Table 1. Proporção aluno/computador

\begin{tabular}{|c|c|}
\hline Escolas participantes & Proporção aluno/computador \\
\hline E1 & 47 \\
\hline E2 & 50 \\
\hline E3 & 54 \\
\hline E4 & Não há computadores na SI ${ }^{2}$ \\
\hline E5 & 65 \\
\hline E6 & 123 \\
\hline E7 & 73 \\
\hline E8 & 82 \\
\hline E9 & 187 \\
\hline E10 & 35 \\
\hline E11 & 43 \\
\hline
\end{tabular}

De acordo com o indicador quantitativo exposto na tabela 1, a relação aluno/computador apresenta-se de forma assimétrica nas escolas participantes. No melhor caso, naquelas que possuem computadores na sala de informática, pode-se observar uma relação 1 máquina para 35 alunos; cabe ressaltar que nessa escola a SI nunca esteve em funcionamento. No pior caso dessa relação tem-se 1 máquina para 187 alunos; para essa escola a SI também não se encontra disponível, devido a problemas de refrigeração no ambiente. Em decorrência desse panorama, muitos alunos não utilizam os computadores no desenvolvimento de atividades complementares às de sala de aula, como a realização de pesquisa e trabalhos das disciplinas.

Diretamente associada a essa relação aluno/computador está a questão da manutenção. Houve referências generalizadas aos problemas enfrentados nas escolas com a manutenção dos equipamentos. Em todas as escolas, no momento desta pesquisa, havia máquinas sem uso aguardando reparos. Por exemplo, em uma escola com 24 máquinas disponíveis a metade encontrava-se com defeito; em outra, de um total de 18 máquinas, apenas 7 apresentavam condições efetivas de uso. De acordo com os entrevistados um ponto que tem agravado o número de máquinas efetivamente em uso

\footnotetext{
${ }^{1}$ Razão entre o número total de alunos matriculados e o número de computadores em funcionamento na SI.

${ }^{2}$ Todos os computadores foram furtados dessa escola. O furto de computadores de escolas tem se tornado um problema sério. Nesse sentido, há depoimentos em que se assegura que pessoas utilizam-se dos próprios alunos para obter informações a respeito da escola, e, em especial, da sala de informática educativa.
} 
se deve a ausência de um suporte técnico regular. Além da oferta desse serviço vir se mostrando aquém das necessidades das escolas, há o problema de um longo período por reposição de peças e, igualmente, espera, quando é necessária uma atualização física dos equipamentos.

Cada conjunto, que varia de 10 a 20 escolas — das que estão localizadas na área metropolitana de Belém - é subordinado a uma Unidade SEDUC na escola (USE), que é um setor da SEDUC dentro de uma escola, e que assume a responsabilidade pelo apoio administrativo às demais. Dentre os auxílios prestados às escolas vinculadas a uma determinada USE está a disponibilização de um técnico responsável pela manutenção de todas as máquinas relacionadas ao uso da informática, sendo estas ou não da SI. Isso tem sido apontado, por todos os entrevistados lotados nas SI, como um fator negativo, dada a demasiada espera quando solicitadas melhorias dos equipamentos de informática. Pelo relato dos entrevistados não há uma política de manutenção preventiva e tampouco um agendamento sistemático do técnico nas escolas por ele atendidas. Isso se reflete em até alguns meses de espera para a solução dos problemas detectados.

Há também que se pensar em estratégias de utilização da SI quando da sua utilização pelos professores que atuam em sala de aula, pois as turmas quase sempre são compostas de 30 a 40 alunos. Para que a quantidade de máquinas efetivamente em uso não interfira negativamente no desenvolvimento da aula, os participantes relataram utilizar-se da divisão de turmas. Assim, uma parcela da turma é dispensada enquanto a outra utiliza o espaço; na aula seguinte inverte-se o esquema. Mesmo entendendo-se o mérito dessa iniciativa não se pode deixar de mencionar que, caso essa prática se torne constante, isso irá influenciar na carga horária da disciplina na qual os alunos estão matriculados. Para fazerem uso das SI as sub-turmas deixarão de participar de uma parcela da carga horária total da disciplina.

A questão tempo é colocada como ponto crucial para a realização de projetos concretos envolvendo laboratórios de informática nas escolas:

\footnotetext{
"Os professores colocam como grande obstáculo ao uso da sala de informática, o tempo gasto para essa tarefa. Desenvolver um projeto no laboratório de informática, via de regra, é muita gente para poucas máquinas, internet lenta, às vezes o sistema operacional não roda o vídeo programado para aula, e todo esse tempo investido acaba comprometendo o cumprimento na íntegra do conteúdo programático da disciplina; é difícil equacionar tudo isto, justamente porque não há tempo suficiente, não tem pessoal qualificado para auxiliar neste trabalho" (informação verbal) ${ }^{3}$.
}

Foram inúmeras as críticas relacionadas ao bom funcionamento e uso das SI. O relato de um participante, ocupante do cargo de direção em uma das escolas visitadas, expõe a questão da carência vivenciada na rede estadual:

\footnotetext{
"Nós temos entraves na escola e o primeiro, posso dizer que é recurso. Nós não temos recursos. Não temos recursos para fazer pequenos reparos. Até a compra de gás para manter o repasse da merenda escolar está comprometida e o dinheiro acaba saindo do meu bolso. Estamos fazendo uma venda pra poder ajudar. A escola há um mês não tinha tonner para emissão dos boletins,
}

\footnotetext{
3 Informação fornecida pelo participante P3.
} 
também foi necessário comprar com o meu dinheiro. Eu arquei com todos os problemas da escola, inclusive financeiramente. A escola foi uma nova família que eu ganhei. Em relação à sala de informática ela está sem ar condicionado, quando eu mandei fazer o orçamento para consertá-lo foi calculado em quinhentos reais $(\mathrm{R} \$ 500,00)$ e ai eu resolvi aguardar a manutenção da SEDUC, que já foi informada desde o início do problema. O laboratório está sem uso há um ano porque os alunos não aguentariam ficar lá devido a elevada temperatura do ambiente" (informação verbal) ${ }^{4}$.

A ausência de software educacional e do uso dos poucos disponíveis nas SI é um fator que torna a escola dependente da internet como ferramenta de apoio à aprendizagem. Essa solução fica subordinada ao bom funcionamento da conexão da rede nos dias e horários agendados para as aulas nas SI. Nesse sentido os participantes revelaram recorrentes problemas com o funcionamento da internet, que envolvem desde paralisações no circuito da rede instalada até o furto de equipamentos, como modem. Em relação aos inúmeros furtos produzidos nas SI adotou-se uma prática que consiste em só se permitir o acesso às SI se houver um professor responsável no turno correspondente. Nas escolas que não têm esse profissional disponível, as salas de informática ficam sem utilidade. Cabe ressaltar que em nenhuma das escolas participantes há esse profissional lotado nos três turnos de funcionamento. No melhor caso têm-se dois turnos cobertos e isto em apenas duas escolas participantes. Notou-se que o turno da noite quase sempre é desprestigiado na disponibilidade deste profissional nas salas de informática. Apenas em uma escola houve o relato de haver no período da noite esse profissional disponível. Esse mesmo professor informou que o espaço é muito pouco procurado e descreve o estado físico da SI na qual trabalha:

“Com um espaço físico inadequado é difícil qualquer trabalho fluir. O espaço é muito quente. Tem um aspecto de sujo. Falta uma revitalizada na pintura. Tem uma impressora que não tem tinta. Não tem papel. Não tem quadro magnético. Alguns computadores ligam outros não. A entrada dos pendrives não funciona em todas as máquinas. Tecnologia adequada aqui é difícil" (informação verbal $)^{5}$.

As escolas não foram projetadas inicialmente para admitir um espaço destinado ao uso da informática. Um participante, ocupante do cargo de vice direção, em uma das escolas visitadas, descreveu a longa e ainda não encerrada história sobre a implantação de uma SI. Segundo esse participante, o processo de informatização nessa escola começou por iniciativa de um professor em 2005. Entretanto, uma exigência para entrega dos computadores à escola é a submissão de um projeto que deve ser devidamente aprovado pelo órgão estadual competente que coordena os trabalhos envolvendo informática aplicada à educação. Após o deferimento do projeto foi exigido que a escola apresentasse o espaço para o recebimento das máquinas. Dessa forma foi desativado o arquivo da escola. Porém quando o técnico foi inspecionar o local foi de parecer de que era inadequado para a instalação da SI, por não atender o tamanho mínimo exigido. Posteriormente foi desativada uma sala de aula de adequado tamanho. Mais outro período de espera foi consumido entre a solicitação e a instalação das bancadas que serviriam de área de trabalho para os computadores e sem as quais não se

\footnotetext{
4 Informação do participante P11.

5 Informação do participante P9.
} 
poderia recebê-los. Finalmente, em dezembro de 2010, foram entregues a essa escola 18 computadores. Alguns meses ainda foram necessários para que o técnico da USE a qual essa escola está vinculada fosse ao local para realizar a instalação dos equipamentos. Por ocasião dessa visita o técnico verificou que a escola não possuía instalação elétrica apropriada de forma a sustentar a sobrecarga exigida quando da efetiva instalação e uso dos computadores. O técnico achou prudente não executar a ordem de serviço e recomendou à direção os reparos na rede elétrica de forma a que esta não viesse a ter um desequilíbrio de carga. Ainda de acordo com a vice direção, foram os gestores que providenciaram as medidas necessárias solicitadas pelo profissional, custeando com recursos pessoais a compra dos materiais requeridos. Por ocasião da entrevista a esta pesquisa a escola permanecia sem nunca ter utilizado a $\mathrm{SI}^{6}$.

Uma espera tão acentuada como a anterior também foi relatada em outra escola. Há três anos os computadores permanecem encaixotados. Recentemente um professor lotado nessa escola concluiu os trâmites necessários para habilitar-se ao trabalho na SI. E segundo relato da direção, aguarda-se apenas a visita do técnico da USE a qual a escola está ligada para que finalmente os 11 computadores sejam instalados e posteriormente utilizados pelos 400 alunos matriculados no período integral ofertado pela escola.

A pesquisa mostra também que não apenas os aspectos físicos, retardos de cronograma e de instalações complicam a vida da escola - e que estão à margem das competências didáticas, mas que as condições pessoais e profissionais de trabalho do professor se ajuntam à problemática. Foi verificado que a jornada de trabalho do professor constitui-se em sua totalidade nas horas utilizadas para o ensino com os alunos. A exceção é para os que atuam nos espaços especiais (sala de leitura, $\mathrm{SI}^{7}$, biblioteca e outros) ou cargos de gestão (direção ou vice direção escolar). De acordo com todos os participantes, não é contemplada para os professores, uma parcela de carga horária semanal às atividades complementares, realizadas fora de sala de aula, como as de planejamento e avaliação.

6 A direção informou que nos próximos meses a escola entrará em restauração, tendo como prazo de aproximadamente 1 ano de reforma. Por este motivo os computadores aguardam encaixotados o momento de serem utilizados. Deve-se ressaltar que o professor que iniciou o processo de implantação da SI faleceu durante o processo e em homenagem póstuma o espaço recebeu seu nome.

7 Com relação aos espaços pedagógicos das escolas da rede estadual, tais como a sala de informática (SI), de acordo com a portaria $\mathrm{n}^{\circ}$ 023/2011, para cada turno deve ser lotado um professor, que obedecerá a seguinte regra de lotação: 30 (trinta) horas semanais nos turnos da manhã e tarde, e 25 (vinte e cinco) horas semanais para o período noturno. Entretanto de acordo com o diretor executivo do sindicato e com os professores lotados nas SI, para o ano de 2012, contrariando a portaria de lotação e à revelia da direção escolar, o setor de lotação da SEDUC alterou o carga horária para os espaços pedagógicos. Houve uma redução para 20 horas semanais aos docentes lotados nesse espaço independente do turno de lotação. Segundo o SINTEPP na folha de pagamento do mês de maio já foi realizada a alteração de carga horária. Aqueles professores que não forem lotados imediatamente em sala de aula, para compensar as 50 horas mensais extraídas dos espaços pedagógicos, mesmo com o semestre letivo tendo sido iniciado aproximadamente 30 dias (16 de abril), terão prejuízos financeiros no final do mês. O salário do professor é gerado a partir do montante da carga horária trabalhada no mês corrente, se um professor é 200 horas mensais, e por algum motivo, não fecha sua carga horária, ele apenas fará jus proporcionalmente a jornada efetivamente trabalhada na escola. 
A sobrecarga de trabalho mencionada pelos professores pode ser um fator que diretamente influencia na qualidade dos trabalhos por eles realizados com relação ao uso das SI ou até mesmo relaciona-se à impossibilidade de uso desse ambiente. A jornada de trabalho excessiva, os baixos salários, a legítima busca pela complementação de renda tem debilitado o processo mediador que deve haver entre o currículo escolar e sua apropriação pelos estudantes. A mediação pedagógica que poderia ser operada nesse ambiente tem sido comprometida diante da situação de penúria pela qual passam os docentes da rede estadual paraense de ensino: condições de trabalho precárias e salários precários. Assim, consequentemente, dimensões importantes relativas às atividades-fim da escola, passam a ser negligenciadas ou passam a ter um papel secundário no processo educativo. Envolvidos com a quantidade de atividades extraclasse, e tendo necessidade de complementação da renda salarial, os professores entrevistados se mostram comprometidos com a educação pública. Um fato que reflete esse compromisso é todos terem mencionado restringirem seu tempo supostamente livre para atingirem os objetivos da produção escolar. Há reivindicações dos professores para que seja reconhecido o trabalho excedente das salas de aulas, e que esse tempo seja acrescido à carga horária de trabalho dos docentes. Assim vemos que o que era um medo dos professores - que os computadores viessem a tirar-lhes o trabalho - agora constatam que seu trabalho aumentou. De quantidade. E de qualidade. Assim defende esta nossa pesquisa.

\section{Considerações ao Fim}

É possível então perceber o quão desiguais se encontram as condições materiais das escolas brasileiras que se aventuram no processo de implementação dos computadores no ambiente escolar. Pode-se dizer que se aventuram, pois o domínio das variáveis que constituem o programa de implantação não depende das iniciativas nem mesmo da boa vontade nem da formação do docente nem das dimensões curriculares de estímulo e de organizaçao das disciplinas ou de seus métodos. As dificuldades são mesmo de acesso nesta primeira fase. Em que pese os enormes recursos investidos em equipamentos, os ousados programas de formação, as políticas traçadas com coerência, nosso país ainda deve à escola pública como um todo a criação de condições materiais e de condições de trabalho para os professores, para os gestores, para os alunos, para as comunidades educativas. Ações conjuntas de políticas públicas, esforços das universidades em sua pesquisas, envolvimento dos gestores escolares, movimentos de professores na luta por melhores condições de trabalho, a formação inicial mais cuidadosa nas universidades, os cursos de atualização em educação a distância (EAD), as reorientações curriculares mais corajosas e menos vagas podem trazer novo clima e eficácia para o trabalho de implantação do uso do computadores na educação. Mas o mordomo não é o culpado. Ninguem é culpado. Somos todos responsáveis por esse desafio histórico e urgente.

\section{Referências}

Almeida, F. J. de. (2009) "Paulo Freire/Fernando José de Almeida". São Paulo: Publifolha.

(2007) "Computador, escola e vida: Aprendizagem e tecnologias dirigidas ao conhecimento". São Paulo: Cubzac. 

Cortez.

(2012) "Educação e Informática os computadores na escola”. 5 ed. São Paulo:

Costa, A. L. M. da.; Galvão, O. F.; Ferreira, B. P. (2008) “ ARIT - Um Software Baseado em Equivalência de Estímulos Dirigido a Crianças com Histórico de Fracasso na Aprendizagem de Conceitos Aritméticos", In: XIX Simpósio Brasileiro de Informática na Educação (SBIE), Fortaleza, Julho, p. 125-134.

Saviani, D. (2008) "Escola e democracia. Edição Comemorativa". São Paulo, Cortez e Autores Associados.

Lukács, G. (2004) "Ontología del ser social: El trabajo", 1. ed. Buenos Aires: Herramienta.

Lüdke, M.; André, M. E. D. (1986) “ Pesquisa em Educação: abordagens qualitativas." São Paulo: EPU.

Soriano, R. R. (2004) "Manual de pesquisa social". Tradução de Ricardo Rosenbusch. Petrópolis, RJ: Vozes.

Vieira Pinto, Á. (2005) "O conceito de tecnologia". 2. ed. 2 vol, Rio de Janeiro: Contraponto. 